Asian J. Med. Biol. Res. 2019, 5 (2), 117-125; doi: 10.3329/ajmbr.v5i2.42493

\author{
Asian Journal of \\ Medical and Biological Research \\ ISSN 2411-4472 (Print) 2412-5571 (Online) \\ www.ebupress.com/journal/ajmbr
}

\title{
Article \\ Characterization of bacterial isolates from skin lesions of sheep, goat and cattle in different rearing condition
}

Tapu Kumar Saha ${ }^{1}$, Ferdousi Begum ${ }^{2}$, S. M. Lutful Kabir ${ }^{1}$, Md. Shafiqul Islam ${ }^{1}$ and Md. Shahidur Rahman $\mathrm{Khan}^{1 *}$

${ }^{1}$ Department of Microbiology and Hygiene, Bangladesh Agricultural University, Mymensingh, Bangladesh

${ }^{2}$ Veterinary Training Institute, Khakdohor, Department of Livestock Services, Dhaka, Bangladesh

*Corresponding author: Professor Dr. Md. Shahidur Rahman Khan, Department of Microbiology and Hygiene, Bangladesh Agricultural University, Mymensingh, Bangladesh. E-mail: msrkhan001@yahoo.com

Received: 03 June 2019/Accepted: 25 June 2019/ Published: 30 June 2019

\begin{abstract}
The study was performed to isolate and characterize some selected bacteria from skin lesion of sheep, goat and cattle of different rearing condition. Intensive and semi-intensive housing systems were considered for this study. A total of $(n=60)$ skin wound swab and pus samples were collected for this study during the study period. Among them $(n=30)$ samples were collected from intensive farms and $(n=30)$ samples were collected from semi-intensive farms. Staphylococcus aureus infections were found 70\% skin lesion for sheep, 30\% for goat and 60\% for cattle and Pseudomonas aeruginosa infections were found 5\% skin lesion for sheep, 15\% for goat and $15 \%$ for cattle. Semi-intensive farm animals were more infected by bacteria than intensive farm animals. Staphylococcus aureus affected $53.33 \%$ in intensive farm animal and $66.67 \%$ in semi-intensive farm animal. Pseudomonas aeruginosa affected $10 \%$ animal in intensive housing system and $13.33 \%$ in semiintensive housing system. The organisms were isolated and characterized by morphological, cultural and biochemical characteristics and identified by polymerase chain reaction. Staphylococcus aureus produced yellowish colony in nutrient agar and golden yellow colony in mannitol salt agar. Positive isolates were produced $\beta$-hemolysis in blood agar. Pseudomonas aeruginosa produced characteristic colony in nutrient agar but not produce pigment. Pseudomonas aeruginosa produced colorless colony in MaCconkey agar, violet colony in EMB agar and produced hemolysis in blood agar. Staphylococcus aureus showed Gram positive, cocci shaped and grapes like arrangement and Pseudomonas aeruginosa showed Gram negative, short rod shaped. Staphylococcus aureus fermented five basic sugars and produced gas and Pseudomonas aeruginosa fermented dextrose and mannitol. Both organisms were catalase positive, only Pseudomonas aeruginosa was oxidase positive. Pseudomonas aeruginosa isolates were further characterized by PCR amplification of toxA gene primer. Staphylococcus aureus skin infection treatment was noticed more effective by erythromycin and gentamicin and Pseudomonas aeruginosa skin infection treatment more effective by ciprofloxacin and gentamicin. Both the organisms were found to be amoxicillin resistant. This is the first and preliminary report of molecular characterization of Pseudomonas aeruginosa from skin lesion of sheep, goat and cattle associated with a different rearing condition of the animals in Bangladesh.
\end{abstract}

Keywords: bacteria; skin lesion; cattle; sheep; goat; rearing condition

\section{Introduction}

The bacterial organisms that cause wounds on skins and hides of domestic animals have been investigated throughout the world (Sanousi et al., 1989; Peregudon et al., 1985). Bacteria such as Staphylococcus aureus, Corynebacterium spp., Brevibacterium spp. and Acinetobacter spp. live on normal skin and cause no harm. The most common bacteria to cause skin infections are: Staphylococcus aureus causes folliculitis, furunculosis (boils), impetigo, toxic shock syndrome etc. Streptococcus pyogenes cause cellulitis, erysipelas, impetigo, 
necrotizing fasciitis and scarlet fever. Other less common bacterial infections that cause skin signs include: Erysipelothrix insidiosa cause of erysipeloid (usually an animal infection), Haemophilus spp. cause of cellulitis in young children, Klebsiella rhinoscleromatis cause of rhinoscleroma, Pseudomonas aeruginosa causes wound infections, athlete's foot, Gram negative folliculitis, chronic paronychia, Bacillus anthracis cause of anthrax, Clostridium perfringens and other species cause gas gangrene, Borrelia spp. cause Lyme disease, Mycobacterium spp. causes tuberculosis, leprosy and atypical mycobacterial infections, Serratia marcescens is a facultative anaerobic Gram negative Bacillus that may rarely cause skin infections such as cellulitis, abscesses and ulcers. These are more likely to arise in patients with immunodeficiency and Tularemia spp. a tick borne infection due to Francisella tularensis (Stulberg et al., 2002; Swartz, 2000; Wilkerson, 2002). Al-Harbi (2011) isolated Corynebacterium pseudotuberculosis, Staphylococcus aureus subsp. anaerobius, Staphylococcus aureus, Streptococci, Pseudomonas aeruginosa, Actinomyces pyogenes were also isolated from infected abscesses from goat and sheep abscess. Intensive and semi-intensive housing systems are followed in domestic animal rearing in Bangladesh. The associated environment of farm causes various bacterial infections. Mazur $e t$ al. (2013) reported that the intensity of the epizootic situation in livestock-related pseudomonosis has increased due to changes in the methods of cultivation and animal keeping. In addition, in present conditions of intensive industries animals are exposed from birth to various stress factors which reduced their natural resistance, contributing to the rapid spread of pseudomonosis adaptation and reproduction of the pathogen in the body followed by isolation of bacteria in the environment. The methods of breeding, housing and feeding domesticated animals vary from species to species and differ according to custom and in accordance with geographical and climatic conditions. All kinds of wounds on skin and hides usually occur due to breach with very sharp instruments, imperfect brand marks, rubbing against course surfaces or incisions made by doctors during surgical operations. Breach in skins and hides, various kinds of wounds and injuries get contaminated by a big population of bacterial flora such as the pyogenic bacteria especially, Streptococcus pyogenes, Staphylococcus aureus and the Coliform group together with Proteus vulgaris welchii type A, Clostridium septicum, Clostridium diphtheriae, that cause damage to the qualities of leather which reflect in sense of losses to the leather industries and ultimately economy of the country. All kinds of abscess on skins and hides are the main cause of organisms as well parasites and become reason of contamination (Saini et al., 1992) Bangladesh has a fairly large livestock population to support a strong and growing tanning industry. Hides and skin Merchants Association Survey report 2005 showed that cow hides account for 56\% of the production, goat skins for $330 \%$ and buffalo makes up the rest. The current output in Bangladesh is about 200 million sq. $\mathrm{ft}$. of leather annually. Apart from bovine hides, buffalo, goat and sheep (Paul et al., 2013). Bacterial infections of skin degrade the quality of hides, skin and wool. That causes huge economic loss. Dermatitis, abscess, folliculitis, furunculosis (boils), impetigo, burns, parasitic infestation, cut, injury degraded hides and skin quality. The study of causal agent of skin infection helps to prevent degradation of hides and skin. Information on sheep and goat skin diseases in other countries is voluminous, but such information is very limited in Bangladesh. In addition to these, information on skin diseases of cattle is scanty in Bangladesh. Prevalence of bacterial skin diseases, lice, ticks and mite infestation in cattle, goat and sheep has been reported from Bangladesh (Huq and Mollah, 1972; Quader, 1973; Saikh et al., 1983). Most recently epidemiological and clinical features of skin diseases of cattle, goat, sheep caused by bacteria, lice, ticks and mite have been described by Nooruddin and Dey (1990). A work on Dermatophilosis in cattle was carried out by Mannan (2009) in Bangladesh. Moreover, Hossain et al. (2013) preliminarily reported Pseudomonas aeruginosa from abscess of cattle using cultural characterization instead of molecular characterization. The present research work was taken into consideration for further study focusing of cultural, biochemical and molecular characterization of selected bacterial isolates from skin lesions of sheep, goat and cattle in different rearing condition

\section{Materials and Methods}

\subsection{Sampling areas and sample collection and transportation}

The present research work was carried out considering the criteria of intensive and semi-intensive rearing system where 10 cattle, 10 goat and 10 sheep of Barisal Dairy and Breed Development Farm (BDBDF), Barisal Sadar, Barisal, Dairy Farm, BAU Mymensingh, Goat Farm, BAU, Mymensingh, sheep farm of Tangail sadar upazilla and 10 cattle, 10 goat and 10 sheep from semi-intensive farm of Narail sadar, Mymensingh sadar and Tangail sadar upazilla. Skin swab and pus samples of sheep, goat and cattle were collected aseptically using sterile cotton buds and placed in test tube containing nutrient broth and transported to the Laboratory of the Department of Microbiology and Hygiene, Bangladesh Agricultural University maintaining $4{ }^{\circ} \mathrm{C}$ temperature in an ice box. 
2.2. Isolation of Staphylococcus spp. and Pseudomonas spp.

The collected skin swab and pus samples were enriched into nutrient broth by incubating at $37^{\circ} \mathrm{C}$ for 24 hours. To isolate and study the cultural properties of Staphylococcus spp. and Pseudomonas spp., enriched cultured were streaked onto different selective and differential culture media like Mannitol salt agar, MacConkey's agar, EMB agar and Blood agar according to the methods described by Cowan 1985 where all of the media were brought from the Indian company, Himedia.

\subsection{Identification of Staphylococcus spp. and Pseudomonas spp. by conventional methods}

For identification of isolated Staphylococcus spp. and Pseudomonas spp., Gram's staining and biochemical tests were performed. Gram's staining was performed according to the method described by Merchant and Packer, 1967 where all of the reagents like crystal violet, Gram's iodine, safranin, acetone alcohol, immersion oil were brought from the German company, Merck. Different types of biochemical tests like sugar fermentation test, MR-VP reaction, indole reaction, Oxidase and catalase test were performed according to the methods described by Douglas et al., 1998 and OIE, 2012 where all of the reagents were brought from the German company, Merck.

\subsection{Molecular detection of Staphylococcus spp. and Pseudomonas spp. by PCR assay 2.4.1. Preparation of DNA templates}

Extraction of DNA from the Staphylococcus spp. and Pseudomonas spp. was carried out by conventional boiling and rapid cooling method (Medici et al., 2003). In brief, $200 \mu$ ldeionized water was taken into an eppendorf tube, a pure bacterial colony from nutrient agar was mixed with the deionized water. The tube then transferred to boiling water and boiled for 10 minutes then immediately to the icebox for cold shock about 10 minutes and then centrifuged at 10,000 rpm for 10 minutes. Supernatant were collected and used as DNA template during PCR.

\subsubsection{PCR amplification of toxA gene of Pseudomonas aeruginosa and nuc gene of Staphylococcus aureus} Details of the oligonucleotide primers used for the amplification of toxA gene of Pseudomonas aeruginosa and

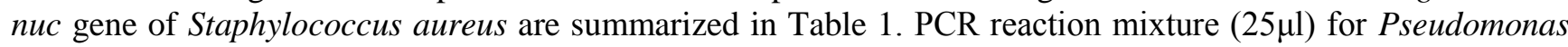
aeruginosa was prepared using $12.5 \mu \mathrm{l}$ master mixture (Promega, USA), 10 pmol primer (Bioneer, South Korea) of each, $5 \mu 1$ DNA template and $5.5 \mu 1$ nuclease free water.

PCR reaction mixture $(25 \mu \mathrm{l})$ for Staphylococcus aureus was prepared using $5 \mu$ l genomic DNA, $12.5 \mu \mathrm{l}$ PCR master mixture (Promega, USA), $1 \mu \mathrm{l}$ primer each $(1 \mu \mathrm{l}$ forward and $1 \mu 1$ reverse primer) and $5.5 \mu 1$ of nuclease free water. For the amplification of of toxA gene of Pseudomonas aeruginosa, the cycling conditions consisted of initial denaturation for 2 minutes at $95^{\circ} \mathrm{C}$, followed by 30 cycles of denaturation at $95^{\circ} \mathrm{C}$ for 40 seconds, annealing at $50^{\circ} \mathrm{C}$ for 1 minute, extension at $72^{\circ} \mathrm{C}$ for 2 minute and final extension at $72^{\circ} \mathrm{C}$ for 10 minutes where the cycling conditions for the amplification of nuc gene of Staphylococcus aureus consisted of initial denaturation at $95^{\circ} \mathrm{C}$ for 5 minutes followed by denaturation at $95^{\circ} \mathrm{C}$ for 1 minute, annealing at $55^{\circ} \mathrm{C}$ for 45 seconds and extension at $72^{\circ} \mathrm{C}$ for 1 minute. The final extension was conducted at $72^{\circ} \mathrm{C}$ for 10 minutes. The PCR reaction was performed for 30 cycles. Amplification was performed in a thermal cycler (Eppendorf, Germany). The amplified products were electrophoresed into $1.5 \%$ agarose (Sigma-Aldrich, USA) gel at 100 volt visualized under Gel doc/UV trans-illuminator (BioRad). 100 bp (for Salmonella spp.) and $1 \mathrm{~kb}$ (for E. coli) DNA size marker (Promega, USA) were used.

\subsection{Antibiogram profiles}

Antibiogram was performed by employing the Kirby-Bauer disc diffusion method (Bauer et al., 1959) using eight different commercially available antibiotic discs (HiMedia, India and Oxoid Ltd., England) on MuellerHinton agar (HiMedia, India) to assess the susceptibility and resistance pattern of the isolates. The selected antibiotics used were ciprofloxacin (5 $\mu \mathrm{g} / \mathrm{disc})$, amoxicillin $(30 \mu \mathrm{g} / \mathrm{disc})$, gentamicin $(10 \mu \mathrm{g} / \mathrm{disc})$, erythromycin (30 $\mu \mathrm{g} / \mathrm{disc})$, and tetracycline $(30 \mu \mathrm{g} / \mathrm{disc})$. The interpretation on susceptibility was done according to the guidelines of Clinical and Laboratory Standards Institute (CLSI, 2012).

\section{Results}

\subsection{Isolation and cultural characterization of Pseudomonas spp. and Staphylococcus spp.}

The growth of Pseudomonas spp. and Staphylococcus spp. was indicated by the presence of turbidity in the nutrient broth after overnight incubation at $37^{\circ} \mathrm{C}$. On Nutrient agar, Pseudomonas produces circular, smooth, mucoid colony with characteristics of grape like odor. Pseudomonas produces pale, colorless, smooth colonies 
on MacConkey's agar and Smooth, circular, pink color colony on EMB agar. On blood agar, Pseudomonas produces white colony with hemolysis was produced. Staphylococcus produces circular, small, smooth, yellowish colonies on mannitol salt agar with changing the color of the medium from from bright red into yellow. On blood agar, white to golden colony with beta hemolysis were produced by Staphylococcus.

\subsection{Identification of Staphylococcus spp. and Pseudomonas spp. by conventional methods}

In Gram's staining, the isolated Staphylococcus spp. revealed Gram positive, violet colored, cocci shaped organisms arranged in grape like clusters and Pseudomonas spp. revealed Gram negative, pink colored, short rod shaped organisms with singly arranged.

Fermentation of five basic sugars with the production of acid indicated that the isolates were Staphylococcus spp. positive while Pseudomonas spp. fermented dextrose and mannitol with the production of only acid but did not ferment maltose, lactose and sucrose. Staphylococcus spp. were found as MR test and indole positive where Pseudomonas spp. were found as MR test and indole negative. Both organisms (Staphylococcus spp. and Pseudomonas spp.) were found as catalase positive, VP test negative. Pseudomonas spp. specifically found as oxidase test positive.

\subsection{Molecular detection of Staphylococcus aureus and Pseudomonas aeruginosa by PCR assay}

DNA extracted from all of the isolates (36 Staphylococcus aureus and 7 Pseudomonas aeruginosa) were used in PCR assay. Polymerase chain reaction with the primers nuc gene (for Staphylococcus aureus) and toxA gene (for Pseudomonas aeruginosa) identified all of those isolates as positive for Staphylococcus aureus and Pseudomonas aeruginosa showing amplification of 279 bp and 150 bp respectively as presented in Figures 1 and 2.

\subsection{Results of distribution of selected bacteria present in different samples of different rearing condition}

Animals reared in semi-intensive was affected skin diseases more than intensive farm. Staphylococcus aureus infection occurred $66.67 \%$ in semi-intensive and $53.33 \%$ infection in intensive farm. Pseudomonas aeruginosa infection found $13.33 \%$ in backyard farm and $10 \%$ infection in good husbandry farm. Nonspecific bacteria were found to be $36.66 \%$ in intensive farm and $20 \%$ in backyard farm. The results of bacterial distribution are shown in Table 2 and Table 3.

\subsection{Results of distribution of bacterial isolates from different animal species}

Staphylococcus aureus was isolated more than the Pseudomonas aeruginosa from skin sample of different animal. Staphylococcus aureus $60 \%$ and Pseudomonas aeruginosa $15 \%$ of cattle skin sample. Pseudomonas aeruginosa was isolated from 15\% goat skin sample and Staphylococcus aureus was isolated from $70 \%$ goat skin sample. Staphylococcus aureus was isolated 50\% and Pseudomonas aeruginosa was isolated from 15\% sheep skin samples. This result is shown in Table 4.

\subsection{Results of antibiogram study of the isolated bacteria}

From all bacterial isolates, ten (10) isolates of Staphylococcus aureus were selected randomly and Pseudomonas aeruginosa positive seven (7) isolates were selected for the antibiotic sensitivity test and resistance pattern against commonly used antibiotics. The results of sensitivity against antibiotic discs (zone of inhibition) were categorized as sensitive (S), intermediate (I), resistant (R).

\subsubsection{Antibiotic sensitivity pattern of Staphylococcus aureus}

From the antibiotic sensitivity test of Staphylococcus aureus, it was found that $80 \%$ of the isolated Staphylococcus aureus were sensitive to erythromycin, $70 \%$ to gentamicin, $60 \%$ to ciprofloxacin, $50 \%$ to tetracycline. The organisms showed 30\% intermediate sensitivity to ciprofloxacin, $20 \%$ ton amoxicillin $10 \%$ to erythromycin, tetracycline and gentamicin. The isolates showed $80 \%$ of the Staphylococcus aureus were resistant to amoxicillin, $40 \%$ to tetracycline, $20 \%$ to gentamicin and $10 \%$ to ciprofloxacin, and erythromycin.

\subsubsection{Antibiotic sensitivity pattern of Pseudomonas aeruginosa}

From the antibiotic sensitivity test of Pseudomonas aeruginosa, it was found that $85.72 \%$ of the isolated Pseudomonas aeruginosa were sensitive to ciprofloxacin, $71.43 \%$ to gentamicin and $14.29 \%$ to tetracycline. The organisms showed $57.14 \%$ intermediate sensitivity to tetracycline, $42.85 \%$ to erythromycin, $14.29 \%$ to amoxicillin and ciprofloxacin. The isolates showed $85.72 \%$ of the Pseudomonas aeruginosa were resistant to amoxicillin, $57.14 \%$ to erythromycin and $28.57 \%$ to tetracycline. 
Asian J. Med. Biol. Res. 2019, 5 (2)

Table 1. List of Primers used in this study.

\begin{tabular}{|c|c|c|c|c|}
\hline Primer & Sequence (5'-3') & Target & $\begin{array}{l}\text { Amplicon } \\
\text { size (bp) }\end{array}$ & Reference \\
\hline toxA $\mathrm{F}$ & 5'GGAGCGCAACTATCCCACT3' & \multirow[b]{2}{*}{$\begin{array}{l}\text { toxA gene of } \\
\text { Pseudomonas } \\
\text { aeruginosa }\end{array}$} & \multirow[b]{2}{*}{$150 \mathrm{bp}$} & \multirow[b]{2}{*}{$\begin{array}{l}\text { Sabharwal et } \\
\text { al. (2014) }\end{array}$} \\
\hline toxA $\mathrm{R}$ & 5'TGGTAGCCGACGAACACATA3' & & & \\
\hline$n u c \mathrm{~F}$ & 5'-CGA TTG ATG GTG ATA CGGTT-3' & \multirow[b]{2}{*}{$\begin{array}{l}\text { Nuc gene of } \\
\text { Staphylococcus } \\
\text { aureus }\end{array}$} & \multirow[b]{2}{*}{$279 \mathrm{bp}$} & \multirow[b]{2}{*}{$\begin{array}{l}\text { Dewanand et } \\
\text { al. (2007) }\end{array}$} \\
\hline nис $\mathrm{R}$ & 5'-ACG CAA GCC TTG ACG AAC TAA AGC-3' & & & \\
\hline
\end{tabular}

Table 2. Frequency distribution of bacteria from collected samples of skin of animals reared in intensive farm.

\begin{tabular}{|l|l|l|l|l|l|}
\hline Organism & Cattle & Goat & Sheep & $\begin{array}{l}\text { Total no. of } \\
\text { Isolates }\end{array}$ & Percentage (\%) \\
\hline Staphylococcus aureus & 5 & 6 & 5 & 16 & 53.33 \\
\hline Pseudomonas aeruginosa & 2 & 0 & 1 & 3 & 10 \\
\hline $\begin{array}{l}\text { Nonspecific, mixed } \\
\text { and contaminant }\end{array}$ & 3 & 4 & 4 & 11 & 36.66 \\
\hline Total & $\mathbf{1 0}$ & $\mathbf{1 0}$ & $\mathbf{1 0}$ & $\mathbf{3 0}$ & $\mathbf{1 0 0}$ \\
\hline
\end{tabular}

Table 3. Frequency distribution of bacteria from collected samples of skin of animals reared in semiintensive farm.

\begin{tabular}{|l|l|l|l|l|l|}
\hline Organism & Cattle & Goat & Sheep & $\begin{array}{l}\text { Total no. of } \\
\text { Isolates }\end{array}$ & Percentage (\%) \\
\hline Staphylococcus aureus & 7 & 8 & 5 & 20 & 66.67 \\
\hline Pseudomonas aeruginosa & 1 & 1 & 2 & 4 & 13.33 \\
\hline $\begin{array}{l}\text { Nonspecific, mixed } \\
\text { and contaminant }\end{array}$ & 2 & 1 & 3 & 6 & 36.66 \\
\hline Total & $\mathbf{1 0}$ & $\mathbf{1 0}$ & $\mathbf{1 0}$ & $\mathbf{3 0}$ & $\mathbf{1 0 0}$ \\
\hline
\end{tabular}

Table 4. Percentage of bacterial isolates from different animal species.

\begin{tabular}{|l|l|l|l|l|l|l|}
\hline \multirow{2}{*}{ Organism } & \multicolumn{2}{|c|}{ Cattle } & \multicolumn{2}{c|}{ Sheep } & \multicolumn{2}{c|}{ Goat } \\
\cline { 2 - 8 } & $\begin{array}{l}\text { No. of } \\
\text { isolate }\end{array}$ & $\begin{array}{l}\% \text { of } \\
\text { isolate }\end{array}$ & $\begin{array}{l}\text { No. of } \\
\text { isolate }\end{array}$ & $\begin{array}{l}\text { \% of isolate } \\
\text { No. of isolate }\end{array}$ & $\begin{array}{l}\text { of } \\
\text { isolate }\end{array}$ \\
\hline Staphylococcus aureus & $12(20)$ & 60 & $14(20)$ & 70 & $10(20)$ & 50 \\
\hline Pseudomonas aeruginosa & $3(20)$ & 15 & $1(20)$ & 5 & $3(20)$ & 15 \\
\hline
\end{tabular}




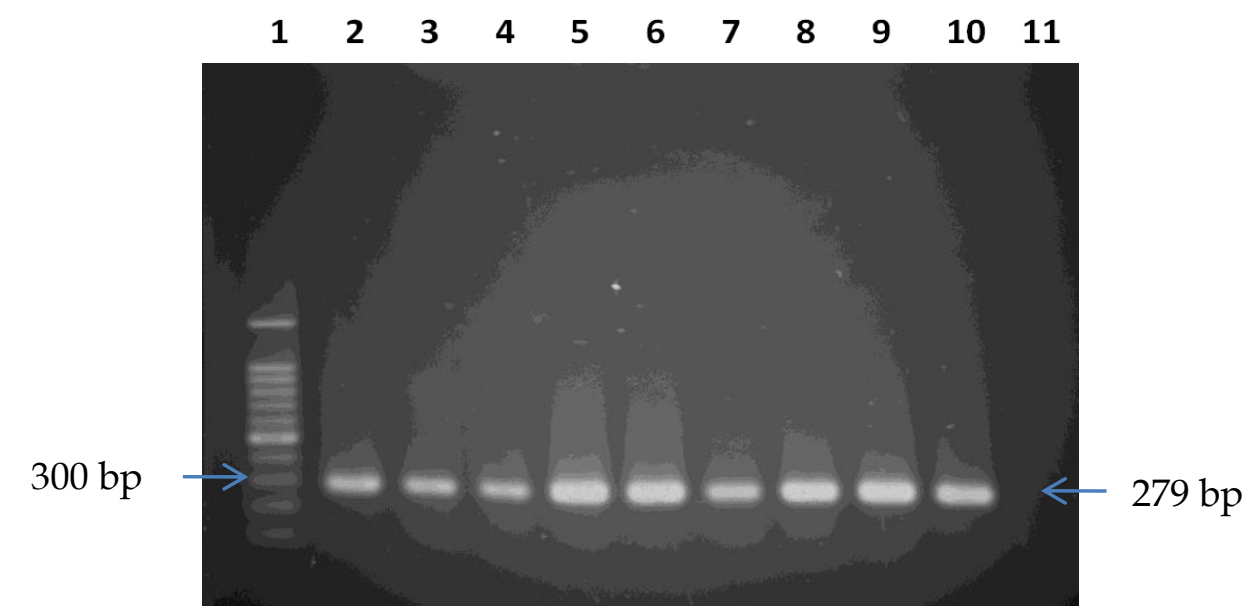

Figure 1. PCR of Staphylococcus aureus specific nuc gene (size = 279 bp). Here, Lane 1: 100 bp ladder, Lane 2-9: test samples positive for nuc gene, Lane 10: Positive control, Lane 11: Negative control.

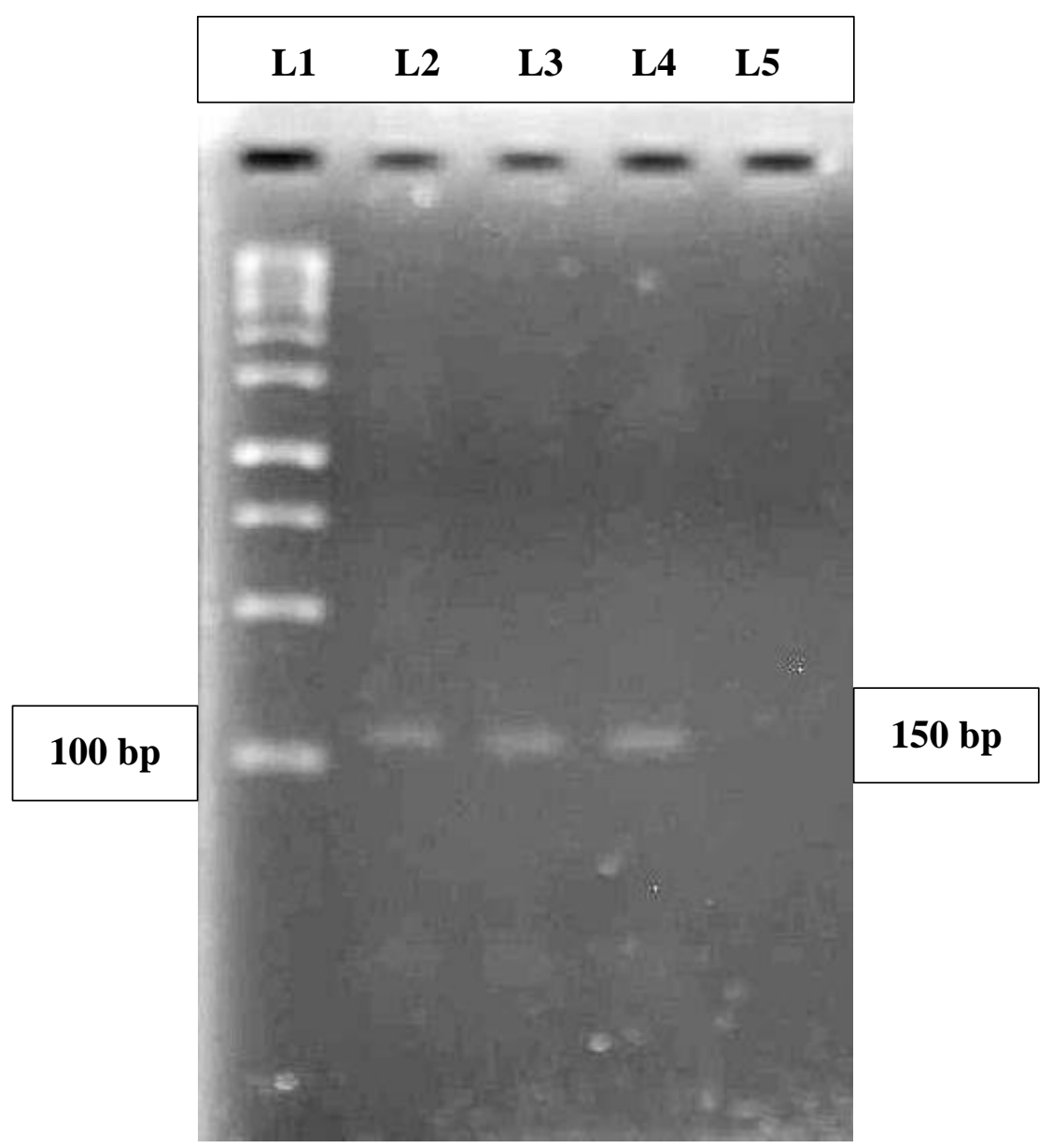

Figure 2. Results of PCR targeting toxA gene for identification of Pseudomonas aeruginosa. L1: 1 kb plus DNA ladder, L2, L3, L4: DNA of Pseudomonas aeruginosa, L5: Negative control.

\section{Discussion}

This is the study of isolation and identification of bacterial isolates of skin lesion from sheep, goat, and cattle. Other important focusing point of this study is rearing system. Intensive and semi-intensive rearing system is concerned in this study. Thirty samples were collected from sheep, goat and cattle of intensive rearing system and 30 samples were collected from semi-intensive rearing system. Skin wound swab and pus samples were collected for this study. Samples of intensive farms were collected from Dairy and Breed Development Farm 
(BDBDF), Barisal Sadar, Barisal, Dairy Farm, BAU Mymensingh, Goat Farm, BAU, Mymensingh, sheep farm of Tangail sadar upazilla and samples of semi-intensive farm are collected from Narail sadar, Mymensingh sadar and Tangail sadar upazilla. In this study Gram positive Staphylococcus aerues and Gram negative Pseudomonas aeruginosa were isolated from skin lesions. The Gram positive Staphylococcus aerues characterized by morphology, cultural properties and biochemical test. In this study selective media were used for isolation of Staphylococcus aureus. The organism produced characteristic yellow color in mannitol salt agar and change the media color. Staphylococcus aureus produced yellow color in nutrient agar. Colony characteristics of Staphylococcus aureus in MS agar and morphological, cultural and biochemical characteristics of Staphylococcus aureus recorded in this study were similar to the findings of Das (2012), Chatterjee et al. (1990), and Jahan et al. (2014). They recorded yellowish colony on MS agar, cocci shaped in a grape like arrangement under the microscope. Catalase positive Staphylococcus aureus fermented five sugars and produced acid in this study. Das (2012) and Chatterjee et al. (1990) reported that fermentation of glucose, maltose, lactose, sucrose and mannitol fermentation with only acid production. In this experiment all isolates produced $\beta$-hemolysis in 5\% bovine blood agar. Jahan et al. (2014) found 100\% $\beta$-hemolysis production by 64 Staphylococci on 5\% sheep blood agar. In this study 5\% bovine blood was used because of some limitations of sheep blood collection. Gram negative Pseudomonas aeruginosa produced circular mucoid colony without pigment. Colorless colony produced in MacConkey agar and haemolysis in blood agar. The isolated organism fermented dextrose and mannitol and not fermented lactose. These characteristics colonies were similar with finding of Hossain et al. (2013) Haleem et al. (2011) and Wahba and Darrell (1965). The isolated Pseudomonas aeruginosa did not produce any characteristic pigment neither on nutrient agar nor on MacConkey agar and some atypical strain of Pseudomonas aeruginosa may not produce pigment on agar media and has been reported by some investigators (Wahba and Darrell, 1965 and Haynes, 1951). The isolated isolates of Pseudomonas aeruginosa were catalase and oxidase positive. This result was found to be similar with Ningthoujam and Shovarani (2008) and Gaby and Hadley (1957). Antibiotic susceptibility tests were performed against all Staphylococcal and Pseudomonas isolates according to instruction of National Committee on Clinical Laboratory Standard Institute (CLSI, 2012). From the antibiotic sensitivity test of Staphylococcus aureus, it was found that $80 \%$ of the isolated Staphylococcus aureus were sensitive to erythromycin, $70 \%$ to gentamicin, $60 \%$ to ciprofloxacin, 50\% to tetracycline. This result almost similar with Jahan et al. (2014) and Thaker et al. (2013). Wei et al. (2014) described that Staphylococcus aureus resistant to penicillin $90.1 \%$, erythromycin $48.6 \%$, ciprofloxacin $36.9 \%$, clindamycin $27.9 \%$, gentamycin $18.9 \%$, chloramphenicol $9.0 \%$ tetracycline $7.2 \%$ of these strains were observed. In this study it was found that the isolates showed $80 \%$ of the Staphylococcus aureus were resistant to amoxicillin, $40 \%$ to tetracycline, $20 \%$ to gentamicin and $10 \%$ to ciprofloxacin, and erythromycin which is almost similar with Wei et al. (2014). It was found that $85.72 \%$ of the isolated Pseudomonas aeruginosa were sensitive to ciprofloxacin, $71.43 \%$ to gentamicin and $14.29 \%$ to tetracycline. Pseudomonas aeruginosa showed highest sensitivity to Ciprofloxacin. This result was similar with Hossain et al. (2013). There were $(\mathrm{n}=60)$ samples collected from skin lesions of three species of animal. More number of samples from various location of Bangladesh was needed for successful accomplishment of this study. The study was performed only characterization of Staphylococcus aureus and Pseudomonas aeruginosa. Others bacteria involved skin infection were not possible to characterized in this study due to time constraint and lack of sufficient facilities. Only Pseudomonas aeruginosa and Staphylococcus aureus were identified by PCR.

\section{Conclusions}

It may be concluded that Staphylococcus aureus and Pseudomonas aeruginosa may cause primary and secondary infection of skin in sheep, goat and cattle. Bacterial infections were more occurred in semi-intensive housing system. Pseudomonas aeruginosa and Staphylococcus aureus were successfully confirmed using PCR technique. Antibiogram profile of Staphylococcus aureus revealed that these isolates were highly sensitive to erythromycin and gentamycin, moderately sensitive to ciprofloxacin and resistant to amoxicillin. Antibiogram profile of Pseudomonas aeruginosa revealed that these isolates were highly sensitive to ciprofloxacin and gentamicin, moderately sensitive to tetracycline and resistant to erythromycin and amoxicillin. Erythromycin and gentamicin were more effective for the treatment of Staphylococcus aureus skin infection and ciprofloxacin and gentamicin were more effective for the treatment of Pseudomonas aeruginosa skin infection of sheep, goat, and cattle. 


\section{Acknowledgements}

The authors are grateful to the Ministry of Science and Technology for financial support. Also thankful to the Head, Department of Microbiology and Hygiene of Bangladesh Agricultural University (BAU) for giving chance to use the laboratories during this research work.

\section{Conflict of interest}

None to declare.

\section{References}

Al-Harbi KB, 2011. Prevalence and etiology of abscess disease of sheep and goats at Qassim Region, Saudi Arabia. Vet. World, 4: 495-499.

Chatterjee C, NC Nag and JP Ray, 1990. Studies on coagulase status and biochemical characters of animal strains of Staphylococci. Indian J. Anim. Health, 29: 157-161.

CLSI, 2012. Performance standards for antimicrobial disk and dilution susceptibility tests for bacterial isolated form animals; approved standard - third edition. Clinical and Laboratory Standards Institute (Formally NCCLS). 69-72. Communication 28 287-98.

Cowan ST, 1985. Cowan and steel's Manual for Identification of Bacteria (2ndedn.). Cambridge University Press. Cambridge, London. pp. 158-160.

Das S, 2012. Characteristics of methicillin-resistant and vancomycin sensitive staphylococcal isolated from laboratory animals and workers, MS thesis, Department of Microbiology and Hygiene, Bangladesh Agricultural University, Mymensingh.

Gaby WL and C Hadley, 1957. Practical laboratory test for the identification of Pseudomonas aeruginosa. J. Bacteriol., 74: 356-358.

Haleem H, J Kadhim, T Ilham and A Banyan, 2011. Isolation of Pseudomonas aeruginosa from clinical cases and environmental samples, and analysis of its 71 antibiotic resistant spectrum at Hilla Teaching Hospital. Med. J. Babylon, 8: 618-624.

Haynes WC, 1951: Pseudomonas aeruginosa -its characterization and identification. J. Gen. Microbiol., 5: 939950.

Hide and Skin Merchants Association (HSMA), Survey report 2005, Dhaka, Bangladesh.

Hossain MG, S Saha, MM Rahman, JK Singha and AA Mamun, 2013. Isolation, identification and antibiogram study of Pseudomonas Aeruginosa from cattle in Bangladesh. Journal of Veterinary Advances, 3: 180-185.

Huq MM and MA Mollah, 1972. A survey on the prevalence of lice in sheep and goat of Dhaka and Mymensingh, Bangladesh. Bangladesh Vet. J., 6: 21-24.

Jahan M, M Rahman, MS Parvej, SMZH Chowdhury, ME Haque, MAK Talukder and S Ahmed, 2014. Isolation and characterization of Staphylococcus aureus from raw cow milk in Bangladesh. J. Adv. Vet. Anim. Res., 2: 49-55.

Mannan MA, MSR Khan, MM Rahman, F Begum and MZ Uddin, 2009. Isolation and identification of dermatophilus bacteria from the skin lesions of cattle. Bangl. J. Vet. Med., 7: 342-347.

Mazur T and NN Sorokina, 2013. Epizootiological features of Pseudomonas Infection. Journal of Comparative Pathobiology, 6: 585-589.

Merchant IA and RA Packer, 1967. Veteriary Bacteriology and Virology. Seventh Edition. The Iowa University Press, Ames, Iowa, USA. pp. 286-306.

Ningthoujam DS and N Shovarani, 2008. Isolation and characterization of a Pseudomonas aeruginosa strain DN1 degrading p-nitrophenol. Res. J. Microbiol., 3: 345-351.

Nooruddin M and AS Dey, 1990. Further study on the prevalence of skin disease in domiestic ruminants in Bangladesh. Bangladesh Veterinarian, 7: 75-81.

OIE, 2012. Manual of standards for diagnostic test and vaccines.

Paul HL, APM Antunes, AD Covington, P Evans and PS Phillips, 2013. Bangladeshi leather industry: an over view of recent sustainable developments. J. Soc. Leath. Tech. Ch., 97: 25-32.

Peregudon TA, KB Mun and MT Isakov, 1985. Staphylococcus infection in goats. Veterinariya, Moscow, USSR. 2: 4-42.

Quder SA, 1973. A survey on the prevalence of ticks of sheep and goat in Comilla Kotwali Pollice Station, Bangladesh. M.S thesis, BAU, Mymensingh.

Saikh H, MM Huq, MJ Karim and MMM Khan, 1983. Parasites of zoonotic importance in domesticated ruminants. Pak. Vet. J., 3: 23-25. 
Saini NS, SN Sharma, MS Oberoy and KS Roy, 1992. Effect of operation theater environment on laparotomy wound infection in bovine. J. Vet. Med., 39: 258-263.

Sanousi EI, AA Hamad and AA Gameel, 1989. Abscess disease in goats in the Sudan. Rev. Elev. Med. Vet. Pays. Trop., 42: 379-382.

Stulberg D and M Penrod, 2002. Caring for common skin condition: common bacterial skin infections. Am. Fam. Physician, 66: 119-124.

Swartz M, 2000. Cellulitis and Subcutaneous Tissue Infections. Mandell: Principles and Practice of Infectious Diseases, 5thed London: Churchill Livingtone, 1039-1040.

Thaker HC, MN Brahmbhatt and JB Nayak, 2013. Isolation and identification of Staphylococcus aureus from milk and milk products and their drug resistance patterns in Anand, Gujarat. Vet. World, 6: 10-13.

Wahba AH and JH Darrell, 1965. The identification of atypical strains of Pseudomonas aeruginosa. J. Gen. Microbiol., 38: 329-342.

Wei W,Y Xiaojie,Y Xiaorong, M Lingling, G Wenying, M Guozhu, L Weiwei and G Yunchang, 2014. Antimicrobial resistance profiles and genetic diversity of bovine Staphylococcus aureus isolated in 5 provinces of China in 2013. Chi. J. Prev. Med., 48: 406-411. 